\title{
Preview: 2011
}

Materials Research Society Fall Meeting

\author{
Hynes Convention Center, \\ Boston, Massachusetts \\ Meeting: November 28-December 2 \\ Exhibit: November 29- December 1 \\ www.mrs.org/fall2011
}

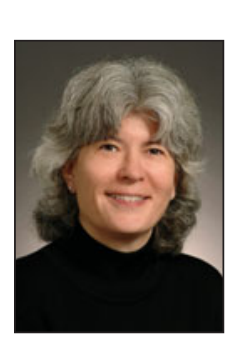

Cammy R. Abernathy University of Florida

FALL MEETING · Meeting Chairs

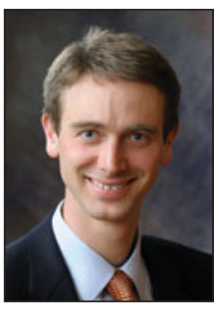

Paul V. Braun University of IllinoisUrbana

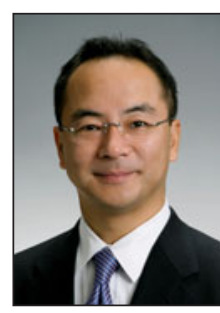

Masashi Kawasaki University of Tokyo

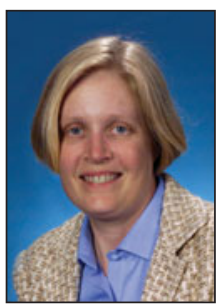

Kathryn J. Wahl Naval Research Laboratory
T The Materials Research Society will hold its 2011 Fall Meeting at the Hynes Convention Center in Boston, Mass., November 28-Deccember 2 , 2011. The meeting will include a technical program, tutorials, a plenary session, an awards ceremony, an equipment exhibit, poster sessions, a career center, funding seminars, and other special activities. Symposium proceedings will be published and made available free online to MRS members.

The increasingly cross-disciplinary worldwide activity on materials research culminates every year in the MRS Fall Meeting. Symposium organizers from around the world have created a program of 46 symposia that addresses leadingedge research and captures the extraordinary progress in materials science and technology, featuring an exciting mix of well-established and popular topics. The symposia are organized into the following clusters.

Energy and the environment addresses materials challenges in nuclear energy, fuel cells, and energy storage. The emerging area of solar-fuel generation will be highlighted. The critical materials issues in organic, inorganic, excitonic, and plasmonic solar energy harvesting will be discussed, with a focus on transformational developments. Highperformance optical materials, the energy applications of hierarchical three-dimensional structures, and sustainable synthesis of nanomaterials will be covered.

Functional materials covers synthesis, fabrication, assembly, and integration of a broad range of materials at different length scales, including topological in- sulators, oxide semiconductors, diamond electronics, compound semiconductors, ferroelectric and mutiferroic materials, and magnetoelectric composites. Novel solution processing strategies for inorganic and hybrid materials, large-area processing and patterning methods, and compliant devices will be featured. The properties of photons in nanomaterials and charges in organic semiconductors will be discussed. New developments in highly energetic materials and multifunctional polymers will be addressed.

Nanomaterials explores functional metal-oxide nanostructures, carbonbased nanostructures, nanowires, nanotubes, semiconductor nanocrystals, and metal-hybrid structures. Developments in understanding transport properties in polymer nano-

MRS composites, and self organization and nanoscale pattern formation will be covered. Mechanical methods for nanofabrication, nanopatterning, and nanoassembly, and the safety and toxicity control of nanomaterials will round out the program.

Biomaterials addresses the materials science of bioelectronics and biological microelectromechanical systems. Both nanomaterials for cancer applications and biomaterials for tissue regeneration are vital topics that will be covered. The formation and properties of synthetic and biological gels, the processing of biomaterials, the nucleation and growth of biological and biomimetic materials, and the multiscale mechanics of hierarchical materials will be featured.

Materials exploration covers materials characterization, including threedimensional tomography, and advanced scanning probe studies. The dynamics of confined systems and interfaces and the

\begin{tabular}{|l|c|c|}
\hline \multicolumn{2}{|c|}{2011 MRS Fall Meeting Registration Rates } \\
\hline & $\begin{array}{c}\text { Pre-Registration } \\
\text { Before 5:00 p.m. (EST) } \\
\text { November 11, 2011 }\end{array}$ & $\begin{array}{c}\text { On-Site Registration } \\
\text { After 5:00 p.m. (EST) } \\
\text { November 11, 2011 }\end{array}$ \\
\hline Member & $\$ 470$ & $\$ 570$ \\
\hline Student Member & $\$ 110$ & $\$ 140$ \\
\hline Nonmember & $\$ 570$ & $\$ 670$ \\
\hline Student Nonmember & $\$ 135$ & $\$ 165$ \\
\hline Unemployed/Retired & $\$ 135$ & $\$ 165$ \\
\hline
\end{tabular}




\section{Hotels in Boston}

The 2011 MRS Fall Meeting will be held at the Hynes Convention Center and Sheraton Hotel in Boston, Massachusetts. For your convenience, special room rates have been arranged at the hotels listed below. Rooms are limited at these rates, so make your reservation early. Your patronage of the official hotels enables MRS to secure the meeting space at a greatly reduced cost. Check the MRS website for more information: www.mrs.org/fall2011.

- Sheraton Hotel

Deadline: November 4, 2011

Tel: 617-236-2000

Single $-\$ 184+\operatorname{tax}$

Double $-\$ 194+\operatorname{tax}$

- Marriott Boston Copley Place Deadline: November 4, 2011

Tel: 617-236-5800

Single $-\$ 178+\operatorname{tax}$

Double $-\$ 195+\operatorname{tax}$

- The Park Plaza Hotel

Deadline: November 4, 2011

Tel: 617-426-2000

Single/Double occupancy - \$167 + tax

- The Westin Copley Place Hotel

Deadline: November 4, 2011

Tel: 617-262-9600

Single $-\$ 181+\operatorname{tax}$

Double $-\$ 201+\operatorname{tax}$

- Hilton Boston Back Bay

Deadline: November 4, 2011

Tel: (617) 236-1100

Single/Double $-\$ 181+$ tax

Triple - \$201+ tax

Quad - \$221 + tax

- Embassy Suites Boston at Logan Airport Deadline: December 5, 2011

Tel: (617) 567-5000

Single/Double - $\$ 129$

Each additional person - $\$ 10$

State and local taxes are currently at $14.45 \%$

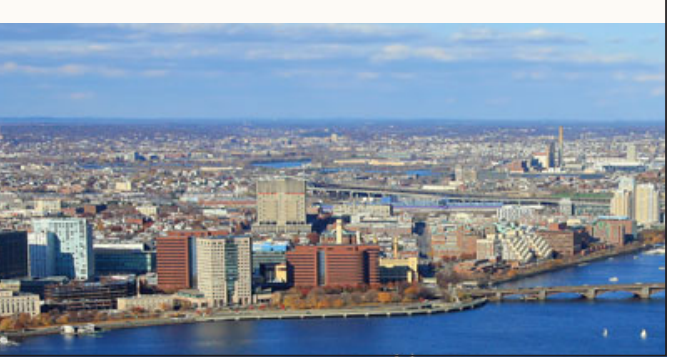

mechanics of materials at the nanoscale will be discussed. New materials and devices for MEMs as well as new combinatorial and high-throughput methods for materials science will be highlighted.

To complement the scientific sessions, tutorials will be offered in several technical areas. Symposium X: Frontiers of Materials Research will feature lunchtime lectures aimed at a broad audience to provide meeting attendees with an overview of leading-edge topics. Poster sessions, an integral feature of MRS meetings, will be held during the evenings. The meeting chairs will award the best posters during each session with prizes of up to $\$ 500$.

\section{Special sessions and events}

The Plenary Session will be held on Monday, Nov. 28 at 6:30 p.m. in the Grand Ballroom of the Sheraton Hotel. This year's plenary speaker is Eric J. Amis, director of Physical Sciences at the United Technologies Research Center. Amis will address recent developments in advanced materials in aerospace, power, and construction from both a basic science and industrial perspective.

The Awards Ceremony will convene on Wednesday, Nov. 30 at 6:30 p.m. in the Grand Ballroom of the Sheraton Hotel, at which the Von Hippel Award, Turnbull Lectureship, MRS Medal, inaugural Materials Theory Award, and Graduate Student Awards will be presented. The ceremony will be followed by the Von Hippel Award address by A. Paul Alivisatos, Larry and Diane Bock Professor of Nanotechnology and Director of the Lawrence Berkeley National Laboratory, University of California-Berkeley on the topic of colloidal nanocrystals.

Phaedon Avouris of IBM's T.J. Watson Research Center in New York, is the recipient of the David Turnbull Lectureship. He will present his lecture on the topic of nanoscience and nanotechnology on Tuesday, Nov. 29 at 5:15 p.m. MRS Medalist Peidong Yang of the University of California-Berkeley and founder of Alphabet Energy, Inc. will present his award talk on nanowires on Wednesday, Nov. 30 at 12:15 p.m. Both award lectures will be given in the Grand
Ballroom of the Sheraton Hotel. Mark Davis of the California Institute of Technology has been selected to receive the Fred Kavli Distinguished Lectureship in Nanoscience. His lecture is scheduled for Sunday, Nov. 27 at 7:00 p.m. in the Grand Ballroom of the Sheraton Hotel.

A special Acta Materialia Materials and Society Award forum on vehicle electrification will be held in honor of award recipient Alan Taub, vice president of General Motors Global Research \& Development. The full-day forum, chaired by Mark W. Verbrugge of GM Global R\&D, will be on Sunday, Nov. 27 beginning at 8:45 a.m. The forum will address the key technology areas required for vehicle electrification and explore the critical materials issues in each area. Developing the required materials solutions will be crucial to realizing the promise of electric vehicles and providing significant energy, environmental, and economic benefits to society.

The Symposium X lunchtime series will open on Monday at 12:15 p.m. with a special forum on the U.S. Materials Genome Initiative for Global Competitiveness. This initiative offers a unique opportunity for the research community to discover, develop, manufacture, and deploy advanced materials at least twice as fast as is currently possible and at a fraction of the cost. The panelists will be Harriet Kung, director of Basic Energy Sciences at the Department of Energy; Ian Robertson, director of the Division of Materials Research at the National Science Foundation; and Cyrus Wadia, assistant director of Clean Energy \& Materials R\&D at the White House Office of Science and Technology Policy.

Two presentations in Symposium X will address materials for energy. MRS Medalist Peidong Yang will speak on Wednesday about nanowires for solar energy conversion. Yang said, "The generation of fuels by the direct conversion of solar energy in a fully integrated system is an attractive goal." Yang will describe several recent examples using semiconductor nanowires and their heterostructures for the purpose of solarto-electricity and solar-to-chemical energy conversion. On Thursday, Hideomi 
Koinuma, professor emeritus of the University of Tokyo and founding member of the Sahara Solar Breeder project, will also discuss challenges to a global energy future. The goal of his project is to utilize the high silicon content of desert sand to provide energy worldwide. The project is a collaborative effort between Japan and Algeria.

Symposium X speaker David G. Cahill of the University of Illinois at UrbanaChampaign will present "eXtremes of heat conduction-Pushing the boundaries of the thermal conductivity of materials." Recently, long-established limits in the thermal conductivity of materials have successfully been pushed back. Cahill will describe measurements of nanoscale thermal transport properties using various ultrafast optical pumpprobe metrology tools covering a broad thermal conductivity spectrum from nanotube interfaces to low-dimensional quantum magnets. Cahill's presentation is on Tuesday.

A number of exciting free events will take place on SUPER SUNDAY, November 27. Events include tutorials and professional development seminars including the Women's Professional Development Workshop, which will feature consultant Jan Yager. Yager, who has a PhD degree in sociology, will lead the workshop on "Effective Time Management for the New Millennium."

The Women in Materials Science and Engineering Breakfast will feature Gwendolyn Boyd, executive assistant to the Chief of Staff at Johns Hopkins University Applied Physics Laboratory, on the topic of Women in Engineering: A Premier Power Source.

Government agency seminars will be held including representatives from the National Science Foundation (NSF), the Department of Energy (DOE), the National Institutes of Health (NIH), and additional agencies who will offer attendees information on funding opportunities in materials research.

Additional instructional seminars include Making the Most Out of Broadcast Media Workshop and a Mastering Science Presentations Seminar, both given by communications specialist Tim Miller of Spoken Science. In Broadcast Media, participants can get some training in how to publicize their research in the media, including how to craft a newsworthy message, and how to best prepare for and execute a media interview. In this popular professional development session, attendees learn the fundamentals of sharing science, and how to choose the very best tools to do the job of communication.

In addition, a Science as Art competition will be held. The competition is open to all registered meeting attendees. Prizes of up to $\$ 400$ will be awarded. The deadline for entries closes on October 18, 2011.

On November 29, 7:00 p.m. to 9:00 p.m., a re-training session will be held for evaluators for the Accreditation Board for Engineering and Technology, Inc. (ABET).

\section{Career services, student events,} and networking opportunities MRS will host a Career Center for meeting attendees, to be held Nov. 29Dec. 1 at the Hynes Convention Center. Services include access to current job postings, a resume file for prospective employers, and onsite interview opportunities.

The Meeting Chairs are also arrang- ing an interactive session on careers in academia. This will take place on Sunday, Nov. 27, at 1:30 p.m. to 5:00 p.m.

Gold and Silver Graduate Student Awards will be presented during the Awards Ceremony to graduate students whose academic achievements and current materials research display a high level of excellence and distinction.

Graduate students and members of MRS University Chapters are invited to attend the student mixer, and chapter officers and faculty advisors are invited to attend a meeting of MRS University Chapter representatives to compare notes on recent activities and brainstorm new projects and issues of common concern. Those interested in starting new chapters are also welcome. Details will be available on the MRS website.

\section{For more information}

See the following pages for a list of exhibitors and more Meeting announcements.

The deadline to pre-register for the meeting is November 11, 2011, 5:00 p.m. (EST). International travelers are reminded to allow ample time to obtain a visa, if necessary. For additional details about the meeting, contact MRS Member Services, Materials Research Society, 506 Keystone Drive, Warrendale, PA 15086-7573, USA; e-mail info@mrs. org, tel. 724-779-3003, and fax 724-7798313. Details of various events and activities will be published in the Meeting Guide available on-site. The MRS website can be accessed for updated information on confirmed talks and details of special events, for more information on obtaining a visa, and for pre-registration: www.mrs.org/fall2011.

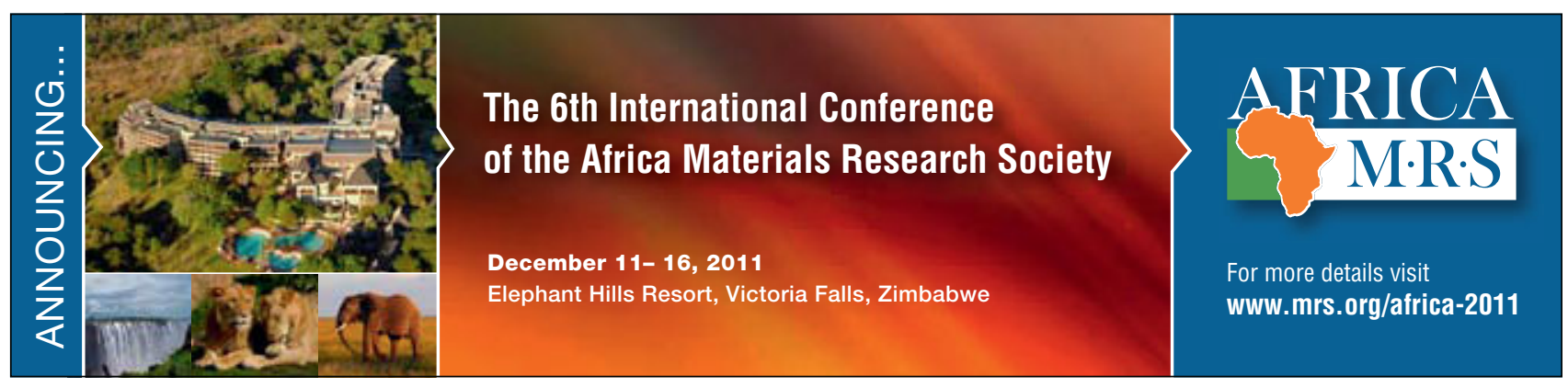


10 Angstroms

A \& N Corporation

AAAS Science \& Technology

Policy Fellowships

Across International LLC

ACS Publications

AdValue Technology, LLC

Advanced Diamond Technologies, Inc.

Advanced Polymer Materials Inc.

Advanced Research Systems, Inc.

Agilent Technologies

AIST-NT, Inc.

AIXTRON SE

AJA International, Inc.

Aldrich Materials Science

Alfa Aesar, a Johnson Matthey Company

Alfred University

American Institute of Physics

American Physical Society

Anasys Instruments Corp.

Andeen-Hagerling, Inc.

Anfatec Instruments AG

Angstrom Engineering Inc.

Angstrom Sciences Inc.

Angstrom Scientific Inc.

Angstrom Sun Technologies, Inc.

Annealsys

Anton Paar USA

Applied NanoStructures, Inc.

Applied Surface Technologies

Arbin Instruments

Asylum Research*

attocube systems AG

Attolight AG

AVS

B\&W Tek, Inc.

Baden-Wurttemberg International

BigC: DinoLite Scopes

Biolin Scientific, Inc.

BioLogic USA

Blue Wave Semiconductors, Inc.

Brooks Automation, Inc.

Bruker

Bruker Nano Surfaces Division

Buchi Corporation

Cambridge NanoTech Inc.

Cambridge University Press

Capovani Brothers Inc.

Carl Zeiss Microlmaging, LLC

Carl Zeiss NTS, LLC

Chemat Technology, Inc.

ColdEdge Technologies, Inc.

COMSOL, Inc.

CRAIC Technologies, Inc.

Cryogenic Control Systems, Inc.

CRYSTAL GmbH

CrystalMaker Software Ltd.

CSM Instruments Inc.

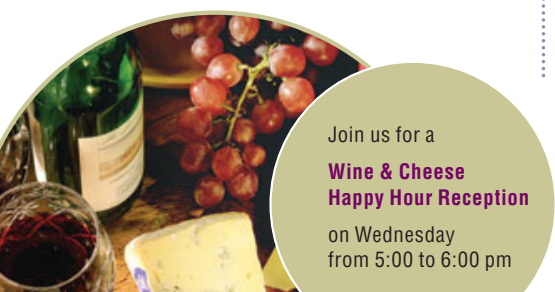

Cyberstar

cyberTECHNOLOGIES USA, LLC

DCA Instruments, Inc.

DECTRIS Ltd

Delong America Inc.

Denton Vacuum, LLC

Digital Surf SARL

DTF Technology GmbH

Ecopia Corp.

eDAQ, Inc.

Electron Microscopy Sciences/ Diatome U.S.

Elsevier

EMD Chemicals Inc.

Energetiq Technology, Inc.

FEI Company*

First Nano, a Division. of CVD

Equipment Corp.

Fischione Instruments

FM Lab

FUJIFILM Dimatix, Inc.

Gamry Instruments

Gatan, Inc.

Geib Refining Corporation

Gelest Inc.

Go!Foton

Goodfellow Corporation

Hamamatsu Corporation

HeatWave Labs, Inc.

Herzan LLC

Hielscher USA, Inc.

Hitachi High Technologies America, Inc.

HORIBA Scientific

Hummingbird Scientific LLC

Huntington Mechanical Laboratories, Inc

Hysitron, Inc

ibss Group, Inc.

Image Metrology A/S

Imina Technologies

Indigo Instruments

Inel, Inc.

INFICON

Innovative Technology, Inc.

Institute of International Education,

Whitaker Program

Intermodulation Products $A B$

International Centre for Diffraction Data (ICDD)

International Union of Crystallography

IOP Publishing

Janis Research Company, LLC*

Japan Science and Technology Agency

Japan Society of Applied Physics

JEOL USA, Inc.*

Keithley Instruments, Inc.

Kimball Physics, Inc

KLA-Tencor Corporation

KP Technology Ltd.

\section{Kurt J. Lesker Company*}

Kyoto Environmental

Nanotechnology Cluster

Lake Shore Cryotronics, Inc.

Laser Quantum Ltd.

Leica Microsystems Inc.

M. Braun, Inc.

MANTIS Deposition Ltd.
Materials Preparation Center, Ames Laboratory

Materion Advanced Chemicals

MDC Vacuum Products, LLC

Metrohm USA, Inc.

METTLER TOLEDO

Micro Materials Limited

Micro Photonics Inc.

MicroFab Technologies, Inc.

Microtrac Inc.

MikroMasch USA

MMR Technologies, Inc.

Montana Instruments Corporation

MTI Corporation

Nano-Master, Inc.

NanoAndMore USA Inc

Nanofactory Instruments $A B$

Nanograde LLC

Nanolnk, Inc.

NANOLANE

NanoMagnetics Instruments Ltd.

Nanomechanics, Inc.

Nanonics Imaging Ltd.

Nanosurf, Inc.

Nanotec Electronica S.L.

Nanotrons Corporation

Nanounity

Nanovea

National Electrostatics Corp. *

National Nanotechnology Infrastructure Network

National Reconnaissance Office

Nature Publishing Group

NBM Design, Inc.

Neocera, LLC

Netzsch Instruments N.A. LLC

NIST/MSD

Nor-Cal Products, Inc.

NT-MDT Co.

Oerlikon Leybold Vacuum

Ohio Carbon Blank Inc.

Olympus America

Omicron NanoTechnology USA

omt optische messtechnik gmbh

OriginLab Corporation

Oxford Applied Research

Oxford Instruments America Inc.

Oxford University Press

PANalytical Inc.

Park Systems Inc.

PCS Instruments

PerkinElmer

Photon Technology International, Inc.

Physical Electronics

Phytron, Inc.

Plasma-Therm LLC

Plasmaterials, Inc.

Plasmionique Inc.

Postnova Analytics Inc.

Powder Processing and Technology, LLC

Princeton Scientific Corp.

Process Materials, Inc.

Protochips, Inc.

PVD Products, Inc.

Quantum Design, Inc.
Hynes Convention Center

Level 2

Tuesday, November 29

11:00 am - 5:30 pm

Wednesday, November 30

11:00 am - 6:00 pm

Thursday, December 1

10:00 am - 1:30 pm

Radiant Technologies, Inc.

Refining Systems, Inc.

Renishaw Inc.

Research and PVD Materials Corporation

Resodyn Acoustic Mixers, Inc.

RHK Technology, Inc.

Rigaku Americas Corporation

Rigaku Innovative Technologies, Inc.

Rocky Mountain Vacuum Tech, Inc.

RSC Publishing

SAGE Publications

Seki Technotron USA

Semicore Equipment Inc

Shanghai Optics Inc.

Solartron Analytical (AMETEK)*

South Bay Technology, Inc.

SP Scientific

SPECS Surface Nano Analysis GmbH

SPEX SamplePrep LLC

SPI Supplies

Springer

STAIB Instruments, Inc.

Strem Chemicals, Inc.

Super Conductor Materials, Inc.

SVT Associates, Inc.

TA Instruments

Taylor \& Francis-CRC Press

TCI America

TDK-Lambda Americas Inc.

Ted Pella, Inc.

The Mellen Company, Inc.

Thermionics Vacuum Products

Thermo Scientific*

Toho Technology

Topcon Positioning Systems, Inc.

Trek, Inc.

Trion Technology, Inc.

TSI Inc.

UES, Inc.

ULVAC Technologies, Inc

VAT, Inc.

VG Scienta, Inc.

Wafer World Inc.

Wiley

WITec Instruments Corp.

J.A. Woollam Company, Inc. *

World Scientific Publishing Co.

XEI Scientific, Inc

XOS

Yeagle Technology Inc.

Zeta Instruments

Zygo Corporation

${ }^{*}$ See Ad in This Issue 